\title{
Las exigencias de la sociedad, las respuestas de la universidad frente a la lectura y la escritura
}

\author{
The demands of society, \\ the answers of the university concerning reading and writing
}

Ruth Milena Páez Martínez*

\section{Resumen}

El artículo centra su atención en mostrar el lugar teórico desde el cual caracterizar e interpretar las prácticas de lectura y escritura en los programas de pregrado de la Fundación Universitaria Monserrate, propósito de la primera fase de la investigación “Reflexión y proyección de las prácticas de lectura y escritura en los programas académicos de pregrado de la fum". Para su desarrollo, en una parte introductoria se presentan los conceptos educación y formación como asuntos necesarios a la hora de pensar y posicionar los procesos formativos de la lectura y la escritura en la universidad, para luego abordar tres referentes conceptuales: los modelos cognitivos ofrecidos por la escritura en el acto de leer, la participación del maestro como puente entre la cultura de los jóvenes y la académica y la evaluación como tensión significativa para el aprendizaje.

Palabras clave

Formación, modelos, lectura, escritura, enseñanza en la universidad.

Abstract

This article focuses on showing the theorical framework, based on which it is possible to characterize and interpret the practice of reading and writing in the programs leading to a degree of the Fundación Universitaria Monserrate. This is a purpose of the first part of a research called "Reflection and projection of reading and writing practices in academic degree programs of the FUM". In order to carry it out, the introduction includes the concepts of education and training as topics needed to think and positioning the educational processes of reading and writing in the university. So that later on it can be possible to deal with three conceptual referents: the cognitive models offered by writing while the act of reading, the participation of the teacher as a mediator between the culture of young people and academic culture, and the evaluation as a significant tension for learning.

Keywords

Training, models, reading, writing, teaching in the university.

Artículo recibido el 16 de septiembre de 2008 y aprobado el 14 de noviembre de 2008.

* Directivo docente en colegio distrital e investigadora. Licenciada en Educación Básica Primaria y Magíster en Educación de la Pontificia Universidad Javeriana.

Correo electrónico: milenapaez@yahoo.es 


\section{Introducción}

Este artículo, de corte teórico y reflexivo, se enmarca en la primera fase de la investigación "Reflexión y proyección de las prácticas de lectura y escritura en los programas académicos de pregrado de la Fundación Universitaria Monserrate", que se adelanta en la misma FUM ${ }^{1}$. Su propósito atiende a una fundamentación conceptual que permita avanzar en el recorrido investigativo $y$, sobre todo, contar con un lugar desde el cual mirar y analizar las prácticas de lectura y escritura en las carreras de Licenciatura en Educación Básica con Énfasis en Lengua Castellana, Licenciatura en Educación Preescolar, Trabajo Social, Finanzas y Negocios Internacionales, y Administración de Empresas y Gestión ambiental de la misma institución educativa.

La pregunta problema que moviliza la investigación total es: ¿Qué sentidos, enfoques, características formativas, limitaciones, potencialidades de proyección y políticas de desarrollo institucional surgen de la reflexión de las prácticas de lectura y escritura que se dan en los programas académicos de pregrado de la Fundación Universitaria Monserrate, en el marco de su identidad como proyecto educativo y en el contexto de las realidades del mundo globalizado, la sociedad colombiana y la universidad contemporáneas? Y la pregunta específica que da lugar a la mirada que se presenta en este artículo es ¿Cuáles son los sentidos, enfoques y tendencias que permiten caracterizar e interpretar las prácticas de lectura y escritura en los programas académicos de pregrado de la FUM, en el marco de su identidad y del contexto?

Para el desarrollo de este texto, desde la mirada de Franz Hinkelammert, Fernando Bárcena y Joan-Carles Mélich, primero se ubicará un contexto general de la universidad frente a su responsabili-

1 El grupo de investigación que le adelanta se denomina Redleesfum. Como investigadora principal está Ruth Milena Páez y como coinvestigadores Héctor Manuel Sarmiento, Liz Loren Aponte, Luz Esperanza Bustos y Camilo Vargas. Un grupo de estudiantes de semillero de investigación de las carreras de pregrado de la Fundación Universitaria Monserrate también forma parte del equipo. Esta investigación se ubica en el paradigma crítico social y su metodología general se comprende como un proceso de investigación acción participativa. dad cultural y ética en este tiempo, lo que llevará a orientar cómo se entienden los conceptos formación y educación. Después se abordarán tres referentes conceptuales: los modelos cognitivos ofrecidos por la escritura en el acto de leer, la participación del maestro como puente entre la cultura de los jóvenes y la académica y la evaluación como tensión significativa para el aprendizaje, todos ellos con los aportes de David Olson y Paula Carlino, especialmente. Con esto, se espera contar con la fundamentación que sirva de soporte al trabajo investigativo mencionado.

\section{Responsabilidad de la universidad con la cultura escrita}

Frente a la globalización, pareciera que la universidad corre y corre tras los nuevos modelos económicos, tras las tendencias marcadas por el mercado global a nivel de competitividad y eficiencia, como si su razón de ser se debiera a ellos. Lo cierto es que a la universidad le compete una "responsabilidad cultural” (Hinkelammert, 2005) gracias a la que se puedan organizar propuestas para el bien común, teniendo como base la vida de la humanidad. Más específicamente, es su labor trabajar por una responsabilidad ética, en la que la educación:

Frente a todos los intentos de pensarla desde estrechos marcos conceptuales que pretenden dejarla bajo el dominio de la planificación tecnológica, donde lo único que cuenta son los logros y los resultados educativos que se "espera" que los alumnos y estudiantes alcancen después de un período de tiempo (Bárcena, F. y Mélich, J., 2000: 12).

De esta manera, se ha de contemplar que debe tomarse en serio el hecho de que el ser humano es un ser histórico, impensable por fuera de un tiempo y lugar situados. Así mismo, en medio del afán de nuestras sociedades por olvidar lo que ha ocurrido en un pasado para avanzar en el cumplimiento de innumerables expectativas de progreso, donde la cultura tecnológica es un sistema omniabarcante y totalizador, y en el cual

"Educar" constituye una tarea de "fabricación" del otro con el objeto de volverlo "competente" 
para la función a la que está destinado, en vez de entenderla como acogimiento hospitalario de los recién llegados, una práctica ética interesada en la formación de la identidad de los sujetos (Bárcena y Mélich, 2000: 14-15)

En esta medida, resulta necesario que la universidad se pregunte ¿cómo contribuir en la formación de los sujetos universitarios?

La globalización ha permitido constituir mercados globales, redes de división social del trabajo en las que las burocracias privadas y multinacionales se encargan de planificarle. Hinkelammert llama a esto "amenaza global" y la sitúa como un problema político que puede atenuarse con una cultura que permita y motive la responsabilidad. La universidad es un lugar esencial en la promoción de esta cultura de la responsabilidad.

No se pueden enfrentar las amenazas globales sin desarrollar una cultura que permita y empuje hacia la responsabilidad en relación con estas amenazas globales. [...] La universidad es un lugar clave en nuestra sociedad pues en ella es formulada y desarrollada nuestra cultura. La función que aparece para la universidad es la de promoción de una cultura de la responsabilidad, basada en una cultura de la esperanza (Hinkelammert, 2005).

En contraste con esto, se ha reducido la educación universitaria a un lugar de producción de "capital humano", entendido como "medio de producción", cada estudiante "invierte en sí mismo, como dueño de sí mismo en cuanto capital humano" $\mathrm{y}$, por tanto, se siguen unos criterios de rentabilidad que atienden más a la lógica de una empresa que de una universidad.

De la cultura escrita. Es cierto que la universidad, y todo el sistema de educación, está implicado en una responsabilidad cultural, así como nuestra propia forma de vivir ha de estarlo. Pero de modo muy particular:

La universidad tiene una función especial por el hecho de que una cultura no se puede desarrollar si no está acompañada por pensamientos profundos, que hasta hoy han tenido su lugar más destacado en las universidades (Hinkelammert, 2005).
Hablar de "pensamientos profundos" resulta interesante cuando se piensa en construcción de conocimiento en la universidad, más allá de un mero acceso e identificación de información.

Se entiende que los pensamientos son profundos cuando han hecho un tránsito de la superficie al subsuelo de alguna idea. En el ámbito universitario, dicho recorrido tiene su mejor campo o nicho creativo a través de los procesos de lectura y escritura.

Dice Vásquez que:

Antes del debate sobre los contenidos en los planes de estudio o de atender a las demandas propias de las profesiones, es urgente desarrollar la lectura como una competencia que funda y atraviesa cualquier carrera y que, a la vez, posibilita tanto el desarrollo personal como colectivo".

Y agrega:

Dado que a la educación superior le corresponde mover los engranajes del pensamiento crítico, de la reflexión, entonces la estrategia de la escritura es idónea para superar el oralismo pasivo, el parloteo sin fundamento, y la opinión apenas pegada a nuestra emoción más inmediata (Vásquez, 2007: 95-97).

En el marco de una cultura escrita, a la universidad le compete propiciar un pensamiento que responda a la construcción de conocimiento, donde lectura y escritura se puedan trabajar pedagógicamente de modo más intencional. Es interesante observar que las distintas formas de escritura (o géneros escriturales si se quiere) solicitados por los docentes universitarios en sus asignaturas implican en sí mismos (o deberían implicar) "pensamientos profundos" de parte de los estudiantes. Un texto resumen, por ejemplo, en apariencia superficial, resulta de la comprensión de otro texto. Este ejercicio no es tan sencillo, sobre todo cuando los estudiantes no están familiarizados con un lenguaje ni con los contenidos propios de alguna materia. De ahí que a nivel universitario se señale incluso la necesidad de enseñarle:

Por ser un ejercicio del pensamiento, de alta abstracción, el resumen requiere de un método muy claro, de una didáctica muy concreta a la hora de 
enseñarse [...] porque resumir, esencialmente nos permite "tragar", llevar a fondo la idea masticada, "hundirnos" bajo el agua del texto para rescatar su esencia. En este sentido, necesitamos de ese paso a paso para no indigestarnos con la escritura incomprendida de otros, ni ahogarnos con la propia (Páez, 2004).

En últimas, es probable que esa tendencia global a la "formación de capital humano" en el contexto de un mercado donde hay que competir y por tanto ser competente, haya desvirtuado el mismo concepto de formación humana y de tradición humanista occidental. Pero siguiendo a Hinkelammert, con una dimensión de la cultura de la responsabilidad que trascienda la mera "capacitación para el ejercicio de una función", es posible hacer un viraje.

De la educación y la formación. Queda claro que no se puede hablar de educar cuando se pretende que los sujetos se vuelvan objetos de un sistema que les entrena para producir y cumplir funciones específicas; un sistema que pretende la homogenización en tanto "fabricación"; un sistema que vuelve "verdad" y único objetivo determinado campo del saber. En contraste con ello, se ha de comprender que los jóvenes que ingresan a la universidad también necesitan ser acogidos, pues ellos son "los nuevos", los recién llegados a una comunidad académica universitaria que antes no conocían, y que se espera les reconocerá como tales y dispondrá de todo lo necesario para su bienvenida. Esta bienvenida es la apertura -intencional- de dicha comunidad, que ya conoce de lo suyo, y que con su experiencia prepara las condiciones necesarias para que estos nuevos entren a la cultura escrita universitaria.

Por supuesto, desde muy temprana edad estos jóvenes han estado inmersos en la cultura escrita. Pero no se puede dar por hecho que entonces ya están listos para asumir los retos académicos que la universidad exige. Pensarlo de esta manera resulta excluyente, dado que quienes no comprendan ni se adapten pronto al sistema terminarán desistiendo y desertando, o creyendo que son unos fracasados. $\mathrm{Y}$ entonces, es muy probable que su inmersión en el ámbito académico resulte una pesadez, algo deslindado de su propia vida. Los estudiantes universitarios han de tratarse como "nuevos" en el sentido del inicio de una nueva vida. Los maestros y la institución como tal han de prepararse para servir de puente de entrada a la comunidad académica universitaria, empleando todo el conocimiento acumulado y transformado tras muchas generaciones.

De la memoria. En esa misma responsabilidad ética, es necesario que la universidad atienda a una "educación de la memoria". La subjetividad no se forma con el olvido del otro, sino mediante el recuerdo, la rememoración, la anamnesis; la formación ha de ser anamnética, mas no amnésica. "Estamos hechos de pasado y volverlo inteligible es también tratar de conocernos mejor" (Todorov, citado por Bárcena y Mélich, 2000: 21). La educación de la memoria permite hacer presente lo ausente; como dice Ricoeur (2004), el pasado se des-vela en un presente y a cada generación le corresponde un tiempo específico. Bárcena y Mélich (2000: 23-30) afirman que "el cultivo de la memoria y del recuerdo nos acerca a los otros, permitiéndonos ir más allá de nuestro yo silencioso, y descubrir así la radical alteridad del otro en tanto que otro". Luego, la educación de la memoria no se puede hacer sobre la mera información ni los hechos "objetivos" e instantáneos, pues entonces no se educa, no hay nada memorable que recordar para luego contar. En la responsabilidad que le corresponde a la universidad, ¿qué es lo que se ha de enseñar para no olvidar? ¿Cuál es el papel de la lectura y la escritura en la educación de la memoria de los sujetos universitarios? ¿Qué es lo que cada disciplina del currículo de las carreras de pregrado no puede pasar por alto? ¿Cómo hacer para que no se olvide lo que no debe olvidarse?

El pasado es [...] objeto de un aprendizaje cuyo tema somos nosotros mismos [...] no es posible una educación que no tenga como punto de referencia el recuerdo y, junto a ello, el compromiso por asentar la construcción de la sociedad en una cultura anamnética, una cultura de la memoria (Bárcena y Melich, 2000).

Ese futuro que se prefigura en los perfiles esperados de los estudiantes, una vez estos culminan sus respectivas carreras, queda endeble sin el recuerdo reflexivo o con sentido del pasado. 
Se requiere una postura educativa ética para trabajar en torno de ello, una educación con recuerdo para que sea humana. "Y para no olvidar, para hacer justicia, es necesario leer y vivir la experiencia del otro en el relato" (Bárcena y Mélich, 2000: 30). En síntesis, cada maestro es tanto "actual" como de "otro tiempo" y:

Contribuye a formar a los recién llegados a partir de la memoria de algo que le precede y está obligado a custodiar. Debe custodiar ese pasado, no para anular nuestras propias posibilidades de acción, sino para promover lo imprevisto, mientras renovamos un mundo común, con el objeto de ofrecer una "respuesta humana" a las contradicciones del tiempo presente (Bárcena, 2006: 225).

Luego de estas reflexiones preliminares que apuntan a una idea de educación y de formación humana, a continuación se presentan tres conceptos a partir de los cuales mirar y caracterizar las prácticas de lectura y escritura en las carreras de pregrado de la Fundación Universitaria Monserrate.

\section{Modelos cognitivos para la construcción de conocimiento}

En esta parte se han tomado esencialmente los postulados de David Olson (1998). Este autor ha dejado claro que, en esta época, las creencias frente a la sobrevaloración de la escritura opacan realmente su importancia frente a la construcción de conocimiento y la comprensión del desarrollo de la mente. De ahí que el énfasis dado en todo su libro se centre en contrastar una serie de prejuicios con su propia postura, para finalmente proponer algunos principios necesarios en una teoría de la cognición y la cultura escrita. Para el caso de la investigación mencionada al principio, resulta de importancia la consideración tanto de los prejuicios actuales sobre la escritura (para distinguir los conceptos de lectura y escritura) como las ideas-fuerza que Olson deja señaladas (para contar con una perspectiva conceptual a la luz de tales principios) y que contribuyen a la construcción de conocimiento en la universidad.

De los prejuicios o creencias que sobrevaloran la escritura (Olson, 1998). Una primera creencia asume la escritura como la transcripción del habla.
Esa idea de que todo lo hablado puede escribirse y que todo lo escrito puede leerse en voz alta. Se considera que aprender a leer es sólo un asunto de representar la propia lengua oral mediante signos visibles. Olson advierte que los sistemas de escritura sólo captan ciertas propiedades de lo que se dice, dejando por fuera el modo de lo que fue dicho, así como las intenciones directas o no de lo dicho. "Lejos de ser una mera transcripción del habla, la escritura es analizada como un modelo para el habla misma; hacemos la introspección de la lengua según los términos anotados por nuestros sistemas de escritura" (p. 28).

Una segunda creencia. La superioridad de la escritura respecto del habla. El habla es desorden, equivocación y hasta divagación, mientras que la escritura es exactitud y concreción. Olson objeta que, frente al poder de la escritura, a. el habla es en sí misma un objeto lingüístico, independiente de la escritura y no derivado de aquella; $b$. no es cierto que todas las lenguas orales son "imprecisas y desordenadas", pues "todas las lenguas humanas tienen una rica estructura léxica y gramatical que es capaz de expresar, al menos potencialmente, todo el espectro de significados"; c. "[...] el discurso oral precede y rodea la preparación, interpretación y análisis del discurso escrito" (Finnegan, 1988 y Heath, 1983, citados por Olson, 1998: 28); hoy se acepta la lengua oral como "posesión y herramienta fundamental del intelecto" (pp. 28-29).

Tercera creencia. La superioridad tecnológica del sistema alfabético de escritura. El alfabeto creado por los griegos como uno de los puntos más altos logrados en la evolución cultural y que, por contraste, supone que los pueblos sin alfabeto no tienen sistema de escritura "verdadero". La sencillez con que tan sólo veinticuatro caracteres gráficos y veinticuatro sonidos, por sí solos desprovistos de sentido, una vez combinados logran decir el mundo con una infinitud de sentidos es considerado por los grandes estudiosos de los orígenes de la escritura una invención que parte en dos la historia de la humanidad en Occidente. Frente a la superioridad del alfabeto y la creencia de su supremacía universal como representación de la lengua hay tres objecio- 
nes. La primera, el alfabeto no fue el milagro del descubrimiento de la fonología de la lengua, sino que fue la adaptación de un silabario diseñado para una lengua semítica correspondiente a una estructura de la lengua griega; la segunda objeción es el uso limitado del alfabeto en la representación de una lengua monosilábica con muchos homófonos, como es el caso del chino que en esta circunstancia, por ejemplo, trae muchas ventajas; la tercera es que la simplicidad del alfabeto tampoco es la causa central de altos niveles de alfabetización, sino que hay otras (el autor no las nombra); y la última, no sólo las culturas alfabéticas consiguen niveles de "alfabetización", asunto que ha sido demostrado por la cultura japonesa, por ejemplo.

Cuarta creencia. La escritura como órgano de progreso social. Esto se observa en las democracias occidentales modernas que establecen como una de sus prioridades la elevación de la alfabetización en la población, dando por sentado que el desarrollo industrial y crecimiento económico está en directa relación con dicha alfabetización. La premisa es: la escritura es causa de desarrollo, sin ella nos condenamos al mundo no civilizado. La objeción que hace Olson está en que la cultura escrita, así como puede ser medio para la liberación, también puede ser medio para la esclavitud. La cultura escrita se instala al interior de la creación de las ciudades y de los gobiernos como un medio para "establecer control social, para transformar a las personas en buenos ciudadanos, trabajadores productivos $y$, si es necesario, en soldados obedientes" (Aries, 1962, citado por Olson, 1998: 30). Quienes desean la mejora en las "habilidades" de la población son los empleadores, con fines más productivos que humanizantes; el temor de los gobernantes con el éxito en la educación del pueblo consiste en temer la crítica que llegue a tambalear la jerarquía social. Así mismo, si bien se reconoce como funcional y ventajosa a la cultura escrita, en ciertos papeles directivos y administrativos, también es cierto que el número de tales papeles es limitado: "el alfabetismo es funcional sólo si se es lo bastante afortunado para obtener determinada posición” (pp. 31-32).
Una quinta creencia. La cultura escrita como instrumento de desarrollo cultural y científico. Se da por hecho que la escritura y la cultura escrita son en buena medida responsables del surgimiento de modos de pensamiento distintos como la filosofía, la ciencia, la justicia y la medicina, y que la cultura escrita es enemiga de la superstición, el mito y la magia. Para autores como McLuhan (1962), Goody y Watt (1963 y 1968), Goody (1986) y Ong (1982), la importancia de la escritura da una nueva orientación al lenguaje, el mundo, la razón y la tecnología de la comunicación (Olson1998: 27). Una objeción. No es preciso atribuir los logros intelectuales de la cultura griega a la escritura. Antes de la misma, se lograron desarrollar el análisis y la argumentación como instrumentos de conocimiento (dialéctica) por medio de la cultura oral; es muy posible que no más del diez por ciento de los griegos en los tiempos de Platón supiese leer y escribir; en síntesis, los modos de pensamiento griego se desarrollaron gracias a la cultura oral.

Sexta creencia. La cultura escrita como un instrumento de desarrollo cognitivo, del mismo modo en que lo era el desarrollo cultural.

Suponemos que el conocimiento legítimo se identifica con el que aprendemos en la escuela y en los libros. La habilidad para leer y escribir proporciona la vía de acceso a ese conocimiento. La principal preocupación de la escuela es la adquisición de las "habilidades básicas".

Frente a ello, el autor objeta que, por un lado, es un error "identificar los medios de comunicación con el conocimiento que se comunica" (pp. 27 y 32). El conocimiento puede comunicarse de diversas maneras: habla, escritura, gráficos, diagramas, videos... La distinción tajante entre habilidades básicas y conocimiento no puede hacerse, pues esto menoscaba la importancia del contenido que es comunicado. Por otro lado, el uso de habilidades relacionadas con la escritura varía mucho de acuerdo con el oficio desempeñado por cada persona, y se simplifica demasiado; el "alfabetismo funcional” cambia según las actividades particulares de cada individuo. 
En general, David Olson centra estos prejuicios en que, por el hecho de acceder a un artefacto tecnológico, o sea un sistema alfabético como lo es la escritura, los occidentales hemos creído durante trescientos años que somos culturalmente superiores a los ancestros iletrados y a los vecinos no occidentales. Teorías de la evolución, el desarrollo y el progreso han alimentado dicha creencia. Y esto, como bien lo dice el autor, sólo puede dar origen a "débiles políticas sociales y débiles prácticas educativas" (p. 23), pues no se pueden otorgar unas cualidades que no le corresponden a la escritura, pasando por alto las que sí le son propias. Frente a ello, la objeción general es que:

La escritura no siempre ni en todo lugar conduce a la democracia, la ciencia y la lógica; algunas culturas no alfabéticas poseen ciencias y filosofías abstractas; la evolución de la cultura griega clásica se produjo a partir de formas especiales de debate político, y no del examen minucioso de documentos escritos; diferentes comunidades de lectores pueden procesar los mismos documentos escritos de maneras muy diferentes [...] (p. 35).

Todas estas creencias se ven reflejadas en escenarios concretos para la enseñanza de la lectura y la escritura en la universidad, en la que se aprecian varias dificultades: Una. "El abandono en que se deja al estudiante una vez que ha sido alfabetizado; a partir de este momento, la imposición de la tarea de leer se constituye en una práctica común y corriente que desliga al maestro de su obligación orientadora y responsabiliza de esa labor exclusivamente al estudiante" (Cárdenas, 2003: 20). Dos. "La tendencia a leer literalmente el texto, a asumirlo como pretexto o a leerlo fragmentariamente" (Ibíd.). Tres. Se da por hecho que los alumnos que ingresan a la universidad ya deberían "saber leer y escribir".

De acuerdo con la línea que desarrolla Olson, han de tenerse en cuenta ocho principios o ideasfuerza que contribuyen a situar desde dónde apuntar a la solución de la pregunta problema central de nuestra investigación. Principio uno. Gracias a la escritura, se han hecho conscientes aspectos de la lengua oral; ésta ha permitido que la misma lengua sea objeto de reflexión, análisis y diseño. Es por ello que en la historia de la escritura se refleja una parte de las implicaciones cognitivas de la misma escritura. Hace más de cuatro mil años, la escritura posibilitó tomar conciencia de la estructura lingüística de las "palabras" mediante las proposiciones (enunciados completos afirmativos o negativos); se pudo distinguir entre lo dicho y lo significado o lo que se quiso decir. Posteriormente, la escritura silábica hizo que se tomara conciencia de la sílaba, y la alfabética que se reconocieran unas partes más pequeñas que las sílabas. En últimas, la relación de la escritura y conciencia es análoga a la de lenguaje y pensamiento; escribir y leer aportan a la conciencia lingüística, pero también a pensar el habla en tanto sistema representacional; la escritura favorece el empleo intencional de la gramática, la lógica y la retórica, pero este proceso no es rápido, sino procesual.

Principio dos. Ningún sistema de escritura puede volver conscientes todos los aspectos de lo dicho, es decir, la fuerza ilocucionaria de un enunciado; se puede presentar lo dicho, pero nunca cómo fue dicho exactamente, y esto es lo más difícil de recuperar en el acto de la lectura. Ha de tenerse en cuenta, una vez más, la necesidad de la interpretación de una expresión determinada en un acto de lectura, desde la niñez. Principio tres. Es muy difícil hacer consciente lo que la escritura no alcanza a representar como modelo. En otras palabras, sólo lo que la escritura puede representar como modelo es lo que podemos hacer consciente; quienes conocen el alfabeto, identifican los fonemas; quienes lo desconocen, no los oyen. Junto con ello, un sistema de escritura permite distinguir lo metafórico del significado literal; y en la construcción de subjetividad, esta distinción es necesaria en el desarrollo de la mente. En últimas, nunca se sabrá la fuerza ilocucionaria del emisor-escritor con exactitud; además, de cara al reconocimiento del modelo que otorga la escritura, tampoco se trata de descubrir exactamente dicha fuerza ilocucionaria, sino de entrar en diálogo con el texto para aproximarse a su comprensión e interpretación.

Principio cuatro. Cuando la escritura como modelo es asimilada, es difícil dejar de pensar por fuera de ese modelo, así como identificar a quien está o 
no familiarizado con el mismo. Hay que ver que el modelo escrito de lengua es sólo uno entre otros, que también proporcionan conocimiento (medios interactivos, por ejemplo) y que los sistemas de escritura no son expresiones del conocimiento fonológico y gramatical. Con la escritura pasamos de hablantes a "usuarios de la lengua". Principio cinco. La escritura proporciona la conciencia de la estructura del habla. Los poderes expresivos y reflexivos tanto del habla como de la escritura son complementarios, mas no similares. Hay dificultades para inferir la fuerza ilocucionaria de lo dicho cuando se pretende una transcripción del habla. Principio seis. La escritura compensa, a su modo, lo que se pierde en la transcripción del habla, mediante la sistematización de un conjunto de verbos de "actos de habla" (afirmar, negar, implicar...) y de otras expresiones que intentan acercarse a un significado (sentido metafórico, sentido estricto...). Una ganancia que se observa en la historia de la lectura es el ejercicio de interpretación literal de los textos, en el cual el lector reconoce que el autor quiere hacer pensar sobre algo y entonces se interesa por el contexto en que escribió la obra y por sus intenciones de autoría. El significado estaba en el texto, derivaba de medios textuales, y no se requerían unos dones especiales del espíritu para su interpretación.

Principio siete. Los textos se leen de un nuevo modo y la naturaleza se lee de modo análogo, por el mismo modelo que el texto escrito ha ofrecido a los lectores. Este nuevo modo es único para todo aquel que desee hacer la lectura respectivamente; todos interpretarán y verán lo mismo en un texto, en tanto el modelo que la escritura proporciona, pues bien se sabe que los variados contextos y lectores determinan múltiples lecturas. Principio ocho. Cuando se reconoce la fuerza ilocucionaria de un texto como expresión de una intencionalidad personal, los conceptos usados para representar el modo en que debe tomarse un texto son los mismos necesarios para la representación de la mente. La teoría cognitiva es el conjunto de conceptos mentales que corresponden a la expresión de la fuerza ilocucionaria; se distinguen entonces intenciones, creencias y deseos.
Finalmente, Olson afirma que la historia de los cambios culturales y conceptuales examinados en su libro constituye una teoría de la lectura en la que se traducen marcas visibles a formas lingüísticas. En este sentido, casi todo puede ser leído (no dice qué no puede serlo).

Además de los contrastes hechos, en los que se hacen distinciones esenciales entre la lectura y la escritura, Olson presenta también unas definiciones específicas: "La lectura consiste en recuperar o inferir las intenciones del autor a través del reconocimiento de símbolos gráficos" (p. 300); significados e intenciones han de ser compatibles con pruebas gráficas. Aprender a leer es "aprender a reconocer los aspectos representados gráficamente y a inferir aquellos aspectos del significado que no están en absoluto representados gráficamente" (p. 300). "La lectura es la recuperación-postulación de una intención destinada al receptor para un texto que es justificable a partir de las pruebas gráficas disponibles" (p. 301). Así mismo, la cultura escrita es una

Condición cognitiva y social, la habilidad para participar activamente en una comunidad de lectores que han acordado una serie de principios de lectura, una hermenéutica, si se prefiere, un conjunto de textos considerados como significativos, $y$ un acuerdo activo sobre interpretaciones válidas o apropiadas de esos textos (pp. 302-303).

De ahí que la relación entre cultura escrita y cognición sea expresada así: "toda escritura puede verbalizarse o leerse en voz alta, entonces toda escritura sirve como modelo para el habla" (p. 303). Todo pensamiento entraña percepción, expectativas, inferencias, generalización, descripción y juicio; y el pensamiento letrado es la manipulación deliberada y la representación consciente de tales actividades (p. 308).

\section{El maestro como puente entre la cultura de los jóvenes y la académica}

En el marco de lo expuesto hasta este momento, en la investigación que nos ocupa se apuesta al reconocimiento de la labor del maestro frente a una serie de suposiciones que se han tejido en torno a la educa- 
ción y la formación de los estudiantes universitarios, así como de las concepciones y posibilidades de la lectura y la escritura para el "nuevo comienzo" en la universidad. Se perfilan ahora algunas acciones de los maestros que inciden en la relación con sus estudiantes, y que de una u otra forma afectan los modos como se asumen las prácticas de lectura y escritura en la $\mathrm{FUM}^{2}$, para luego presentar alternativas sobre la participación del maestro como mediador entre "lo que ya traen los nuevos" y "lo que ofrece la comunidad académica" a la luz de las reflexiones de Paula Carlino (2005).

a. Las relaciones de poder al interior del aula. Cuando las relaciones entre el maestro y los estudiantes, propuestas o marcadas por el maestro, son "verticales" y unidireccionales. El maestro indica qué hay que hacer y eso es lo que "hay que hacer". Los estudiantes se hallan en un lugar pasivo del aprendizaje, con pocos o ningún espacio de diálogo que pueda darle un sentido a las dinámicas que se establecen en el aula y que favorezca una relación horizontal entre ambos. Junto con ello, la desvinculación de lo académico con lo cotidiano se distancia del aprendizaje significativo.

b. El acompañamiento de los docentes. Los estudiantes de semillero que participan de esta investigación observan que algunos maestros proveen estrategias a nivel conceptual en la medida en que el grupo de estudiantes se torna participativo y activo en su proceso de aprendizaje; que se necesita de los estudiantes una conciencia frente a su papel en la universidad en tanto futuros profesionales; se requiere que los maestros generen espacios integrales que provean a los estudiantes diversas estrategias para potenciar su desempeño académico, tales como retroalimentación, socialización y acompañamiento permanente por parte de los docentes con el fin de cualificar las prácticas de lectura y escritura; se ve la ne-

2 Estas reflexiones surgen de las discusiones colectivas entre los investigadores y el grupo de semillero en los seminarios de investigación, a propósito de la lectura y estudio de los libros de David Olson (1998) y Paula Carlino (2005) durante la fase uno de esta investigación. cesidad de cualificar la opinión y los puntos de vista de los estudiantes, a través de la lectura y escritura; se evidencia también la importancia de que los docentes sean lectores y productores de textos activos, lo que les permitirá ser "modelos" frente a sus estudiantes y establecer criterios más coherentes con estas dos prácticas en el aula.

c. La formación de los maestros. Cada disciplina trae consigo un lenguaje que le caracteriza y le es propio. Qué mejor que el mismo maestro de esa disciplina sea quien ponga o identifique en su planeación curricular el trabajo con la lectura y escritura. No hay "fórmulas" ni estrategias que se homologuen de modo exacto a las diversas disciplinas, edades, carreras, épocas. Determinar cuáles son las "mejores" estrategias para la lectura y la escritura en la universidad sólo puede ser una respuesta dada por los maestros que han reflexionado sobre ello y, efecto de esa reflexión, pueden crear y construir las estrategias que necesitan sus estudiantes cada semestre, cada año, dependiendo los mismos alumnos y la proyección de la carrera. Ahora bien, es de reconocer la presencia de limitaciones y carencias de los docentes frente a las prácticas de lectura y escritura.

De la apertura al estudiante universitario. Las reflexiones de Paula Carlino en su libro Escribir, aprender y leer en la universidad, basadas en la enseñanza investigativa, que "se caracteriza por poseer tres importantes rasgos adicionales: ser algo público ("una propiedad colectiva"), abierta a la crítica y evaluación, de modo que otros puedan construir a partir de ella" (Shulman, citado por Carlino, 2005: 173-174) y en la investigación-acción definida como

Una expresión práctica de la aspiración a cambiar, para mejor, el mundo social (o educacional) mediante la mejora de las prácticas sociales compartidas, nuestro entendimiento colectivo de estas prácticas sociales y las situaciones sociales en las que estas prácticas se realizan (Kemmis, citado por Carlino, 2005: 176).

Ello resulta de suma importancia para avanzar en la ruta conceptual desde la cual se observan las 
prácticas de lectura y escritura en las carreras de pregrado de la Fundación Universitaria Monserrate.

Las preguntas que se formula Carlino frente al uso de la lectura y la escritura y sus implicaciones en el desarrollo cognitivo del estudiante universitario son dos: “ ¿qué tienen que ver la escritura y la lectura con el aprendizaje y la enseñanza? y ¿de qué modo podemos los docentes sacar provecho de estas relaciones en beneficio de la formación de los universitarios?" (p. 10). Ambas tienen como antecedentes dos problemas frecuentes en la enseñanza y labor docente: una enseñanza basada en un modelo tradicional, en la que el docente expone una serie de contenidos, desvirtuando el protagonismo del estudiante en la construcción del conocimiento; y la omisión de la enseñanza de una metodología de aprendizaje de su área de estudio, en la cual el profesor "omite enseñarles uno de nuestros más valiosos saberes: los modos de indagar, de aprender y de pensar en un área de estudio" (p. 13).

Se está de acuerdo en que estas preguntas y problemas han de ser compartidos por los alumnos y por las mismas instituciones, pero no solamente por el docente; hay una responsabilidad colectiva frente a las maneras en que se entienden y asumen la lectura y la escritura en la universidad, en otras palabras, respecto de la necesidad de una "alfabetización académica” al estudiante universitario.

\section{De los puentes que se pueden tender}

a. A través de la investigación. Las iniciativas de los maestros en sus asignaturas, sus aciertos intuitivos o equivocaciones metodológicas son factibles de ser reflexionadas mediante la investigación-acción. Carlino brinda unas herramientas teórico-prácticas para trabajar la escritura y la lectura, pero también un modelo que puede orientar nuestros propósitos investigativos a propósito de la enseñanza. En este sentido, la presencia y reconocimiento de modelos de enseñanza permite ver cómo es posible trabajar la lectura y la escritura en una asignatura de modo significativo para el estudiante y sin que esto signifique que se deban calcar tales modelos, pues, precisamente, lo que permite una acción investigativa es construir nuevos modelos (o modos) a partir de las particularidades de los grupos, la época, las políticas universitarias, el propio interés del maestro, entre otros. Con la investigación se está en situación de alerta frente a los posibles cambios y propuestas metodológicas denle el aula.

b. Con la enseñanza de la escritura en el nivel superior. La escritura es un proceso dialéctico que transforma el conocimiento, pues exige relacionar un conocimiento con las posibilidades de expresarlo. De acuerdo con esto, semántica y retórica deben conjugarse para generar un texto que pueda ser leído y comprendido por un lector real. Este proceso exige "poner en relación lo que uno ya sabe con lo que demanda la actual situación de escritura" (p. 24), poner en tensión formativa al estudiante, provocando así una asimilación más productiva de los conocimientos nuevos. Esta concepción de escritura contrasta con aquella que se limita a "decir el conocimiento" (p. 27), en la cual simplemente se reproduce por medio de signos lo que la memoria ha archivado sobre un tema, sin entrar en mayores tensiones.

Posicionar y abordar explícitamente la enseñanza de la escritura a nivel universitario, y desde cada asignatura, significa que el maestro está atendiendo a la enseñanza de estrategias de aprendizaje y al incremento de la participación y el compromiso de los alumnos (p. 25). Pero también significa que, si se desconocen los modos de hacerlo, los modelos ya empleados por otros maestros pueden ser referentes o guías iniciales para la elaboración de los propios modelos de cada maestro. Carlino, por ejemplo, emplea cuatro situaciones modelo fruto de su propia experiencia didáctica: elaboración rotativa de síntesis de clases, tutorías para escritos grupales, preparación del examen y respuesta escrita a preguntas sobre bibliografía, todas ellas atravesadas por acciones como la revisión de la escritura, el papel del lector revisor y la relación pensamiento-lenguaje. Tales situaciones:

Comparten el objetivo de volver necesaria la revisión de la escritura, no sólo en cuanto a la 
ortografía y la morfosintaxis, sino en el nivel de las ideas y la organización discursiva. Las cuatro proporcionan la posibilidad de compartir con otros el rol del lector-revisor. Las cuatro permiten revisar pensamiento y lenguaje juntos, como una forma de irse acercando progresivamente a los conceptos y a la escritura de la disciplina (p. 50).

Siguiendo a la autora, el posicionamiento de la enseñanza de la escritura implica que la institución universitaria ha de considerar estas acciones pedagógicas como constitutivas de los planes curriculares de los maestros, y no como añadidos ni actividades de costura.

c. Con la enseñanza de la lectura en el nivel superior. La lectura se entiende desde un enfoque que requiere la participación del lector, esa lectura interactiva que necesita de la búsqueda del lector, de su propósito y preguntas frente al texto (p. 69). Carlino habla de una "orfandad en la lectura", pues los estudiantes desconocen el propósito de las lecturas propuestas por sus docentes y la relación de éstas con los objetivos disciplinares de la asignatura, y en consecuencia su proceso interpretativo es muy bajo. A propósito de esto, la autora diferencia a los "docentes incluyentes" de los "excluyentes". Los primeros "no responsabilizan a los alumnos por los problemas para entender lo que leen, sino que entienden que leer es un proceso de resolución de problemas" (p. 91); acompañan al estudiante en el tránsito de la hetero-regulación hacia la autorregulación de su propio proceso lector, en el cual las lecturas por encargo serán reemplazadas por lecturas voluntarias; presentan modelos que ayudan a la lectura (como las guías y el resumen, en el caso de Carlino). Los maestros excluyentes, por su parte, pretenden que -sin ayuda- los estudiantes entiendan los textos que ellos les dan a leer, "poniendo barreras a la inmigración y rechazando a los recién llegados" (p. 94); estos docentes no tienden puentes entre la cultura que traen los estudiantes y las distintas culturas académicas de las que somos miembros los profesores; ellos no abren puertas ni incorporan a los "nuevos". d. Con la enseñanza de la lectura y la escritura, por cada disciplina del nivel superior. No son los profesores de lengua castellana ni de la electiva en "habilidades y competencias comunicativas" ni de "taller de redacción" quienes están encargados exclusivamente de trabajar en la enseñanza de la lectura y la escritura en la universidad. Siguiendo los argumentos de Carlino, al maestro de cada asignatura es a quien compete enseñar a leer y escribir para su disciplina. Quién mejor que él mismo: sabe del lenguaje propio de su campo disciplinar, de las temáticas y problemas más complejos de comprender, de las proyecciones y posibilidades sociales, entre tantos otros conocimientos cosechados con la experiencia.

En síntesis, la mediación del maestro universitario frente a la enseñanza de la lectura y la escritura ha de tener en cuenta una serie de principios (Carlino, 2005: 153-172) que se constituyen en la base de la teoría que la autora plantea y con los que esta investigación está de acuerdo:

Principio uno. Nadie aprende por recepción pasiva. Principio dos. Nadie aprende de una vez y para siempre. Los docentes han de contemplar varias instancias de trabajo para cada tema y prever oportunidades en las que sea posible volver a ver lo escrito anteriormente. Principio tres. Nadie aprende una disciplina solo; se precisa entablar un diálogo con quienes ya participan en las comunidades disciplinares. Principio cuatro. Nadie aprende por imposición, sino únicamente si se interesa en hacerlo y si confía en sí mismo para lograrlo. Esto puede lograrse en interacción con los otros; los maestros pueden crear contextos que favorezcan el interés de aprender de los estudiantes y su creencia en que lo conseguirán finalmente. Principio cinco. Es inevitable cierto nivel de desajuste entre las expectativas del docente y el punto de vista de los alumnos, pero es preciso que los profesores ofrezcan medios para intentar acercarlos a ambos. Principio seis. La lectura y escritura son procesos y herramientas intelectuales para aprender, dependientes de los modos culturales en que se emplea y transforma 
el lenguaje. Es un despropósito que la universidad no se ocupe de ellos, pues les desaprovecha como estrategias de aprendizaje y les desconoce como elementos que son la razón de ser de las comunidades académicas. Principio siete. En tanto miembros de una cultura académica, los docentes participan de sus prácticas como si éstas fueran naturales. Pero para los alumnos no lo son y, muchas veces, su desorientación proviene del carácter implícito de las expectativas de los profesores, formadas en la lógica de un determinado campo de estudio. Principio ocho. La autonomía no es sólo un rasgo de maduración biológica que pueda exigirse a los adultos en cualquier contexto. Es también una capacidad que se adquiere para cierto ámbito cuando alguien está familiarizado con las prácticas que allí se llevan a cabo. Los universitarios son recién llegados a las prácticas discursivas universitarias y necesitan del docente para saber cómo participar en ellas. Principio nueve. Tener en cuenta el punto de vista de los alumnos es imprescindible en toda enseñanza que se preocupa por el aprendizaje. Los docentes han de estar al tanto, no sólo de lo que los estudiantes van comprendiendo sobre los temas de sus materias, sino de lo que piensan sobre la forma de enseñarles y sobre las tareas que se les proponen. Asimismo, los alumnos deben ser consultados y corresponsabilizados de ciertas opciones acordadas. Principio diez. Para desarrollarse profesionalmente como docente y para mejorar la enseñanza, se precisa tomarla como objeto de análisis. La enseñanza investigativa y la investigación sobre la acción son algunas de las alternativas que dispone el profesor reflexivo.

\section{La evaluación como} tensión significativa para el aprendizaje

La cuestión planteada por Carlino resulta pertinente “¿de qué modos podemos los docentes promover el aprendizaje de nuestros alumnos por medio de las situaciones de evaluación que les proponemos, que suelen incluir la lectura y la escritura?” (p. 105). Se trata de ayudar a los estudiantes "a saber qué buscar en lo que leen desde la óptica del programa de una materia" y "enseñar a utilizar la escritura como herramienta para pensar" (p. 109). Cuando la evaluación, casi siempre presentada en forma escrita, es vista como un producto acabado que no tiene ninguna posibilidad de revisarse y cualificarse, los estudiantes empiezan a considerar que no son capaces de "escribir bien" y que la escritura es algo terminado, de una vez y para siempre. En ninguno de los dos casos la evaluación está siendo una tensión que aporta al aprendizaje del estudiante.

Dos estrategias didácticas dadas por la autora muestran que la reescritura del examen y la lectura y escritura para presentar una ponencia oral implican leer y escribir desde una buena práctica evaluativa, en la cual los mismos alumnos participen en la elaboración de los criterios con los que serán evaluados; los estudiantes reciben una valoración de sus producciones intermedias, que los orienta a reescribirlas; se le da un lugar en el currículum a la reflexión sobre la forma y el contenido de lo escrito, entre alumnos y docente; el docente no funciona sólo como un juez, sino como un informante que ayuda a tomar conciencia de lo escrito (p. 114). Esto se vuelca a favor de unos alumnos, que prestan mayor atención a lo evaluable y que planifican las prácticas de evaluación; este terreno ganado debe aprovecharse para incluir la enseñanza de la lectura y la escritura en los procesos evaluativos y para considerar otras alternativas de evaluación.

En conclusión, el lugar teórico desde el cual mirar y caracterizar las prácticas de lectura y escritura en los programas de pregrado de la Fundación Universitaria Monserrate tiene su base conceptual (y académica) en los principios expuestos tanto por David Olson como por Paula Carlino. El primero que afirma la presencia de un modelo cognitivo ofrecido por la escritura, que contribuye al desarrollo del habla, a la inmersión en la cultura escrita y a la construcción de conocimiento. La segunda que reivindica el uso de modelos para alfabetizar académicamente a los estudiantes universitarios, de la mano de una acción investigativa, sin dar por hecho que ya saben leer y escribir en la comunidad académica. La ausencia de estos modelos se vuelca en ausencia de comprensión e interpretación cuando se lee y se escribe. Es en el reconocimiento, la construcción y la adquisición de tales modelos que 
está el reto pedagógico de la universidad. Su afán y responsabilidad ética se halla dentro y no en un "modelo económico".

Y tiene su base humanística en los lineamientos de una filosofía de la educación planteados por Joan Carles Mélich y Fernando Bárcena, los que a su vez se nutren de las reflexiones de Hannah Arendt. La educación universitaria no puede reducirse al conformismo y respuesta a modelos totalitarios de afuera ni de "momento". Por su estrecha relación con la temporalidad, la dimensión humana de la educación ha de atender un "tiempo antecedente" y un "tiempo por venir" estrechamente relacionado con la experiencia de "un pasado al que llegamos por la memoria para permitir un nuevo comienzo, y de un futuro impredecible que garantizamos mediante las promesas" (Bárcena, 2006: 223). Con esta mirada, las contribuciones a la formación humana de los estudiantes de pregrado y de los mismos maestros en la FUM se instalan en una doble acción, pues se aporta

\section{Referencias bibliográficas}

Bárcena, F. (2006). Hannah Arendt: una filosofía de la natalidad. Barcelona: Herder.

Bárcena, F. y Mélich, J. C. (2000). Introducción a una pedagogía de la radical novedad. En La educación como acontecimiento ético (p. 12). Barcelona: Paidós.

Cárdenas, A. (2003). Discurso teatral y pedagogía del lenguaje. Folios, 18.

Carlino, P. (2005). Escribir, leer y aprender en la universidad. Una introducción a la alfabetización académica. Buenos Aires: Fondo de Cultura Económica.

Goody, J. (1986). Literacy in traditional societies. Cambridge: Cambridge University Press. Hinkelammert, F. (2005). La universidad frente a la globalización. Revista Polis, 11. a la formación de los recién llegados a partir de la memoria de algo que les precede y que los profesores están obligados a custodiar, y desde acá se promueve lo imprevisto y se construye una "respuesta humana" a las contradicciones del mundo actual.

En este sentido, la necesidad de posicionar la enseñanza de la lectura y la escritura en la universidad resulta una prioridad. No tiene sentido que alimentemos con más quejas y desencantos las deficiencias de los estudiantes en estos dos procesos. Al contrario, es la comprensión de su relevancia tanto para la enseñanza y el aprendizaje como para la formación humana aquello que podrá jalonar nuestra acción pedagógica hacia la investigación y construcción de los modelos que cada disciplina permita crear, y nuestra misión humanística hacia una acción ética. Por supuesto, requerimos compartir esta responsabilidad con los mismos estudiantes y la misma institución universitaria ${ }^{3}$. 1.

Ong, W. (1982). Oralidad y escritura. Tecnologías de la palabra. México: Fondo de Cultura Económica.

Olson, D. (1998). El mundo sobre el papel: el impacto de la lectura y la escritura en la estructura del conocimiento. Barcelona: Colección LEA, Gedisa.

Páez, R. (2004). Sin atorarse ni ahogarse. Por una didáctica para resumir. Revista Hojas y Hablas, 1.

Ricoeur, P. (2004). La memoria, la historia, el olvido. México: Fondo de Cultura Económica.

Vásquez, F. (2007). Educar con maestría. Bogotá: Universidad de La Salle.

3 Para la fase dos de esta investigación se mirará cómo son las prácticas de lectura y escritura en las carreras de pregrado de la fum, para luego esbozar un documento de política universitaria frente a las mismas. 